\title{
Article \\ Parametric Models and Process Map for Alternating Current Square-Waveform Welding of Heat-Resistant Steel
}

\author{
Uttam Kumar Mohantya,b, Yohei Abea, Takahiro Fujimoto ${ }^{a}$, Mitsuyoshi Nakatani ${ }^{a}$, Akikazu Kitagawa ${ }^{a}$, Manabu \\ Tanakac, Tetsuo Sugac, Abhay Sharmad, ${ }^{\mathrm{d}}$,
}

a Technical Research Institute, Hitachi Zosen Corporation, Osaka, Japan.
b Department of Mechanical Engineering, Tezpur University, Assam.
c Joining \& Welding Research Institute, Osaka University, Japan.
d KU Leuven, Campus De Nayer, Sint-Katelijne Waver, Belgium.
* Corresponding Author

\begin{abstract}
The demand for efficient processes through a comprehensive understanding and optimization of welding conditions continues to grow in the manufacturing industry. This study involves heat-resistant 2.25 Cr-1 Mo V-groove steel welding using the square-waveform alternating current. Experiments were conducted to build the relationship between input variables - such as current, frequency, electrode negativity ratio, and welding speed - and process performance, such as penetration, bay area, deposition rate, melting efficiency, percentage dilution, flux-wire ratio, and heat input. The process was analyzed in light of the defect-free high-deposition weld groove weld, the sensitivity to process parameters, and the optimization and development of the process map. The study proposes an innovative approach to reducing the cost and time of optimizing the one-passeach-layer V-groove welding process using bead-on-plate welds. Square waveform welding creates a metallurgical notch in the form of a bay at the fusion boundary that can be minimized by selecting appropriate welding conditions. The square waveform submerged arc welding is more sensitive towards changes in current and welding speed than the frequency and electrode negativity ratio; however, the electrode negativity ratio and frequency are minor but helpful parameters to achieve optimal results. The proximity of the planned and experimental results to within $3 \%$ confirms the validity of the proposed approach. The investigation shows that $90 \%$ of the maximum deposition rate is possible for one-pass-each-layer V-groove welds within heat input and weld width constraints.
\end{abstract}

Keywords: submerged arc; heat-resistant steel; square-waveform welding; aggregate quality index; bay area; melting efficiency; process; model; process map

\section{Introduction}

Submerged arc welding (SAW) is extensively used to manufacture pressure vessels and pipelines. Its inbuilt advantages include smoother bead appearance and cost-effectiveness, deeper penetration, and good weld quality. Through the years of research and innovation, SAW has become more efficient in achieving the aforementioned qualities. Performance measurements in SAW are influenced by welding characteristics and certain process-specific phenomena. The performance measurements and the range of operational parameters differ from one arc-welding process to another. For example, the appearance and shape of the weld bead due to the square alternating current (AC) waveform changes significantly [1]. The SAW, since its inception, has been used with direct current power sources. The SAW operates with a larger wire diameter, so it requires high operating currents. A large portion of the sinewave AC cycle remains at low current, limiting AC use. The alternating current in square waveform provides instantaneous polarity reversal, avoiding low current. The choice of an optimal combination of process parameters ensures the desired weld quality and improves productivity. SAW problems were mainly solved using single-objective optimization to find the optimal solution in the past. However, in most cases, the objectives are conflicting and require more than one objective function to address these issues. Moreover, it is usually impossible to solve multi-objective optimization problems using the traditional approach. The literature reports 
the use of different algorithms, such as artificial neural network [2], genetic algorithm [3], particle swarm optimization [4], meta-heuristic optimization [5], simulated annealing [6], response surface methodology [7], and grey-based Taguchi [8], for the optimization and comparative study of the SAW responses. Process models based on process parameters are needed to optimize a welding process. The conventional direct current submerged arc-welding process has been widely investigated for various process responses, such as bead geometry [9], residual stress [10], deposition rate [11], element transfer [12], mechanical properties [13], arc plasma model [14], flux consumption rate [15], flux design [16], thermal cycle [17], etc.

Square waveform welding has not been extensively investigated for process models as it is one of the latest technologies for SAW. The main areas of investigation for square-waveform welding have been limited to performance evaluation [18], weld bead shape prediction [19], signal processing [20], and thermal modelling [21]. Studies on process models and maps available for conventional submerged arc welding [22] are not reported for square-waveform arc welding. A recent study examined the metallurgical aspects of the square $\mathrm{AC}$ waveform [23]. In comparison to the direct current electrode positive (DCEP) and direct current electrode negative (DCEN) polarities, the square wave welds exhibit larger grain size in the weld metal and coarse and fine grain heataffected zone (HAZ). As a result, the hardness of the weld metal and the HAZ does not increase drastically, unlike the DCEP and DCEN polarities.

The square waveform that is the subject of this investigation has opened up new process applications such as one-pass one-layer welding. Such applications require the weld bead to be wide enough to fill the groove and remain almost flat. In order to use the technology at the workshop level, it is necessary to have a fundamental relationship between the process conditions and the results obtained vis-à-vis the process maps. The AC square wave presents two-tiered challenges. Firstly, the square wave has more operating parameters than the conventional SAW process using DCEP and DCEN (for example, the Electrode negative (EN) ratio. Second, while it is advantageous, the square waveform results in additional effects that must be checked, such as the metallurgical notch in the weld. Therefore, to maximize the square wave AC SAW's benefits, a comprehensive investigation to develop the process model is essential. Such models are also essential to develop process maps that can be used for practical purposes.

Optimizing multiple-pass V-groove obtained through one welding pass in each layer is not revealed in the current literature. The weldment with one pass in each layer needs each pass to produce a surface as flat as possible, which resembles the bead-on-plate weld. The moot point is that if the optimal conditions for multi-pass V-groove weld can be obtained with bead-on-plate welds, the experimentation cost can be significantly reduced. One of the first approaches is developed in this study, where the bead-on-plate weld experiments are extended for V-groove optimization. The primary objective of this work is to obtain the process models for the square ac waveform and demonstrate how the process models and process map of V-groove welding can be obtained using bead-on-plate welding through multi-objective optimization. The proposed approach is implemented in a potential case of V-groove welding in 2.25 Cr-1 Mo heat-resistant steel. The experimental details below are followed by a description of how the proposed process map is developed. The results are discussed in the framework of process models, parametric effects, and optimal process maps.

\section{Experimental details}

\subsection{AC square-waveform welding}

Conventionally, DC power supply sources are used in SAW. The alternating current (AC) application in SAW has been limited because of the crossover problem (polarity reversal), i.e., extinguishing the arc due to the lower voltage when polarity reverses. The application of AC in SAW has been limited to the secondary heat source in tandem welding, where two power sources are used. The polarity reversal issue is solved by developing the power supply that uses a square AC characteristic (Fig. 1). The positive and negative portions of the current cycle can be controlled for their respective duration and amplitude. The fraction of the cycle for which the electrode remains negative is known as electrode negativity ratio (EN ratio). The wire feed speed modulates at variable speeds to achieve a smooth and stable arc, leading to an excellent bead appearance with reduced distortion. The square AC waveform is recommended compared to the positive DC electrode (DCEP) for improved toughness in low-temperature environments. 


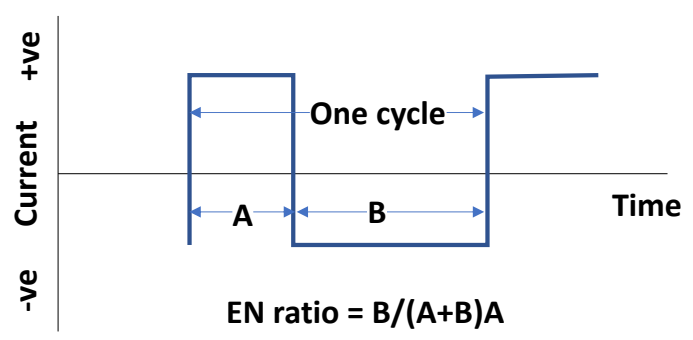

Figure 1. Square waveform showing current cycle and EN ratio.

Square alternating current waveforms can maintain penetration at higher welding speeds [18]. In combination with DCEP (lead wire), the trailing wire with the AC square waveform in tandem welding improves the deposition rate. The waveform control offers a distinct weld bead shape with a bay area (as shown in the later part) that can be computed by composite penetration profile functions depending on materials such as ellipse-ellipse for steel [24] and parabola-ellipse for heat-resistant steel [19].

\subsection{Materials and Experimental procedure}

In this investigation, a $20 \mathrm{~mm}$-thick rectangular $2.25 \mathrm{Cr}-1$ Mo heat-resistant steel plate was the material of the workpiece. A US-521S wire of $4 \mathrm{~mm}$ diameter was used as the electrode material. The combination of wire and flux materials was selected as per the AWS classification AWS A5.23 F9P2-EG-B-3 for the AC power source. The PF-200 $10 \times 48$ mesh flow was chosen as the flux material. The chemical composition of the electrode and baseplate are given in Table 1.

Table 1. Chemical composition.

\begin{tabular}{ccccccccccc}
\hline & $\mathbf{S i}$ & $\mathbf{C}$ & $\mathbf{M n}$ & $\mathbf{P}$ & $\mathbf{N i}$ & $\mathbf{S}$ & $\mathbf{C r}$ & $\mathbf{M o}$ & $\mathbf{C u}$ & $\mathbf{F e}$ \\
\hline Electrode & 0.13 & 0.16 & 0.93 & 0.003 & 0.14 & 0.002 & 2.45 & 1 & 0.12 & Balance \\
\hline Baseplate & 0.14 & 0.13 & 0.5 & 0.007 & - & 0.002 & 2.36 & 0.97 & - & Balance \\
\hline
\end{tabular}

The AC square waveform experiments were conducted for bead-on-plate and V-groove configuration. During the bead-on-plate welding experiments, the dynamic current and voltage were measured to calculate heat consumption. The weights of the base plate and flux were measured using a microbalance. A $650 \mathrm{~mm} \times 100 \mathrm{~mm} \times 5 \mathrm{~mm}$ copper plate was used as the backing material during the narrow groove welding to withstand the base plate's heating effect. In this investigation, four parameters are varied to obtain the data for developing models. These parameters include welding current, welding speed, current frequency, and EN ratio. The welding experiments were conducted at Hitachi-Zosen Corporation, Japan, with variations of current 400-700 A, welding speed of $20-50 \mathrm{~cm} / \mathrm{min}$, frequency $20-60 \mathrm{~Hz}$, and EN ratio $0.25-0.75$. The welding voltage and contact- tipto-work-piece distance were constant at $30 \mathrm{~V}$ and $30 \mathrm{~mm}$, respectively. Electrode diameter was $4 \mathrm{~mm}$. The experimental parameters' variation followed the experiment design, as explained in the following section.

\subsection{Scheme of the experimentation}

The investigation incorporated two-stage experiments. The first stage consisted of the beadon-plate welding experiment, whereas the second stage covered layer-wise deposition of V-groove welds. The first stage of experiments was conducted using AC square and DC power source, whereas the second stage of the investigation used AC square waveform power source. In the first stage, twenty-six experiments were conducted. In addition to sixteen experiments using the $\mathrm{L}_{16}$ orthogonal array, ten were further conducted to make the process robust in design. The mixed-design data are randomly divided into two parts of 21 and 5 experiments each, as shown in Appendix 1 . The set of 21 experiments was used to develop the process models, which the set of 5 was used for model validation. One set of experiments, as a benchmark, was also performed using DCEP and DCEN power sources. The dimensions of the plate used for bead-on-plate welding are shown in Fig. 2 (a). The figure identifies three plates used, out of which the middle plate corresponds to the test specimen, whereas the other two were used as starting and finishing tabs. At the starting and ending position of welding, the deposition behaviour is hampered due to either excessive melting known as wire dripping or lesser fusion known as wire stubbing, which forms discontinuity in welding. 


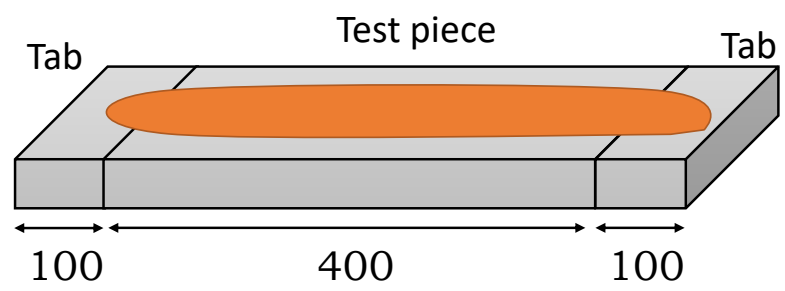

(a)

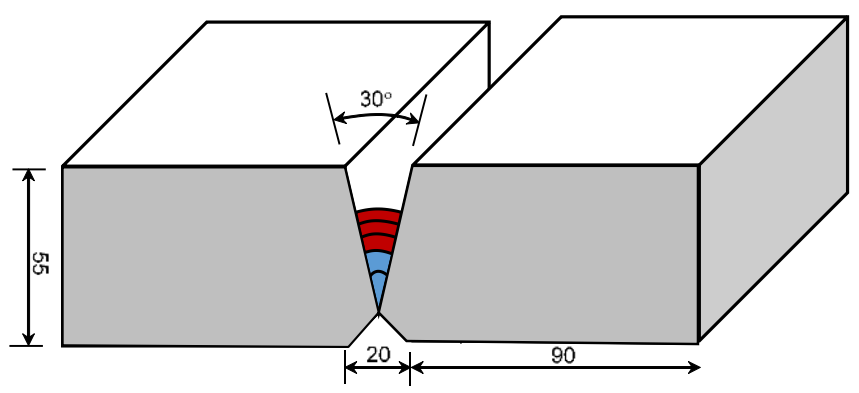

(b)

Figure 2. Test pieces a) bead-on-plate and (b) V-groove configuration.

The V-groove welding (as shown in Fig. 2 (b)) followed the deposition of one layer per pass, wherein five layers were deposited in a single pass each. The welding condition for each groove designed with both base deposit and high deposit conditions are given in Table 2. The test piece, shown in Fig. 2(b), was meant to evaluate the deposition rate. The actual weld design is not shown because of the patent issue. The base deposit and the high deposit are the conditions for which the V-grove deposition rates are compared with prediction based on bead-on-plate. In a separate study, it is confirmed that both conditions ensure desired mechanical properties.

Table 2. Experimental conditions for V-groove deposition.

\begin{tabular}{|c|c|c|c|c|c|}
\hline & Layer no. & $\begin{array}{l}\text { Current } \\
\text { (A) }\end{array}$ & EN ratio & $\begin{array}{l}\text { Welding speed } \\
(\mathrm{cm} / \mathrm{min})\end{array}$ & $\begin{array}{c}\text { Frequency } \\
(\mathrm{Hz})\end{array}$ \\
\hline \multirow{5}{*}{$\begin{array}{l}\text { Base deposit con- } \\
\text { dition }\end{array}$} & $1^{\text {st }}$ & 450 & 0.5 & 27 & 60 \\
\hline & $2^{\text {nd }}$ & 500 & 0.5 & 30 & 60 \\
\hline & $3^{\text {rd }}$ & 600 & 0.5 & 30 & 60 \\
\hline & $4^{\text {th }}$ & 600 & 0.5 & 30 & 60 \\
\hline & $5^{\text {th }}$ & 600 & 0.5 & 30 & 60 \\
\hline \multirow{5}{*}{$\begin{array}{l}\text { High deposit } \\
\text { condition }\end{array}$} & $1^{\text {st }}$ & 450 & 0.5 & 27 & 60 \\
\hline & $2^{\text {nd }}$ & 500 & 0.5 & 30 & 60 \\
\hline & $3^{\text {rd }}$ & 700 & 0.75 & 33 & 20 \\
\hline & $4^{\text {th }}$ & 700 & 0.75 & 33 & 20 \\
\hline & $5^{\text {th }}$ & 700 & 0.75 & 33 & 20 \\
\hline
\end{tabular}

\subsection{Measurement of responses}

2.4.1. Performance measures of bead-on-plate welds

(i) Heat input, deposition rate, and flux-wire ratio: The actual heat input was obtained by capturing the real-time voltage and the current signal recorded through the welding data acquisition system. The relation used to calculate the heat input (HI) can be expressed as

$$
H I=\frac{\eta \sum V_{a} I_{a} \Delta t}{n S \Delta t}=\frac{\eta \sum V_{a} I_{a}}{n s}, \frac{\mathrm{J}}{\mathrm{mm}}
$$

where $I_{a}$ and $V_{a}$ are the instantaneous actual current and voltage in A and Volt, respectively; $\eta$ is the arc efficiency; $n$ is the number of intervals, and $S$ is the welding speed. The deposition rate is measured by weighing the base plate before and after welding. Similarly, the flux consumption rate is calculated by weighing the flux before the welding and recovered flux. The flux consumption rate 
and deposition rate ratio is known as the flux-wire ratio. The results for the different schemes of the experiments are given in Appendix 1.

(ii) Weld bead attributes: The samples were polished and etched with $5 \%$ nital solution $(5 \mathrm{ml}$ $\mathrm{HNO}_{3}+95 \mathrm{ml} \mathrm{CH} 3 \mathrm{OH}$ ) to obtain the weld macrograph, as shown in Fig. 3.

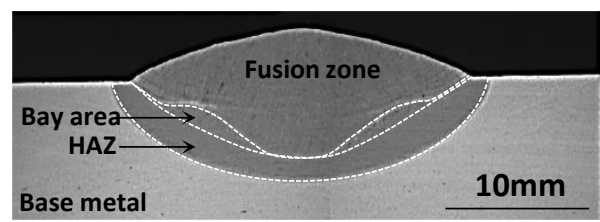

(a)

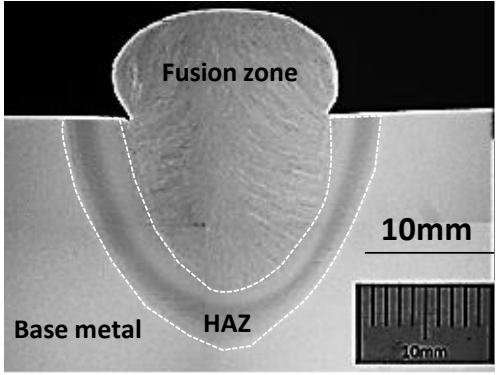

(c)

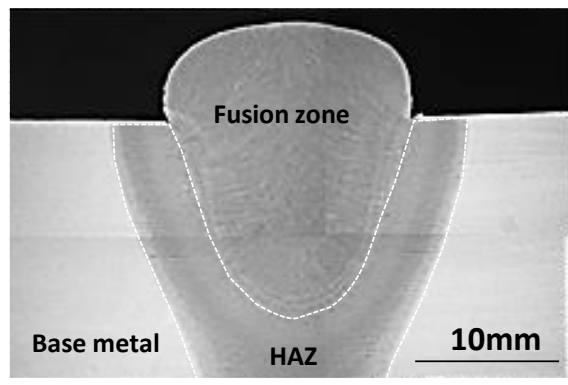

(b)

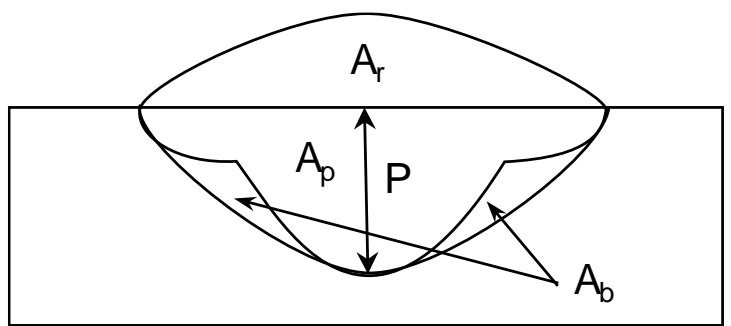

(d)

Figure 3. Macrographs showing weld cross-section produced by(a) AC square (b) DCEP (c) DCEN; and (d) Weld bead characteristics.

The macrograph of the fusion zone highlights different geometric attributes closely related to the reinforcement profile (i.e., the top profile of the fusion zone) and penetration profile (i.e., the bottom portion of the fusion zone). These attributes are depth of penetration $(\mathrm{P})$, bay area $(\mathrm{Ab}), \mathrm{re}-$ inforcement area $\left(A_{r}\right)$, and penetration area $\left(A_{p}\right)$, which are shown in Fig. $3(d)$. The bay area is a metallurgical notch due to a change in the shape of the fusion boundary, which is mainly observed with a square waveform, as shown in Fig. 3 (a).

The dimensions of geometric attributes of the weld were measured from the weld macrograph using Image J software. The expression for calculating \% dilution is given by

$$
\text { Dilution, } \% D=\frac{A_{p}}{A_{r}+A_{p}} \times 100
$$

(iii) Melting efficiency: The melting efficiency indicates the amount of material melted in both electrodes and plate. Therefore, melting efficiency combines both electrode and plate melting efficiency. The melting efficiency can be expressed in terms of the penetration area $\left(A_{p}\right)$, reinforcement area $\left(A_{r}\right)$ and the theoretical cross-sectional area $\left(A_{t h}\right)$ as follows:

$$
\begin{aligned}
& \text { Plate melting efficiency, } \eta_{p}=\frac{A_{p}}{A_{t h}} \times 100 \\
& \text { Electrode melting efficiency, } \eta_{e}=\frac{A_{r}}{A_{t h}} \times 100
\end{aligned}
$$

Therefore, the total melting efficiency can be expressed as

$$
\eta_{m}=\eta_{p}+\eta_{e}
$$

The theoretical cross-sectional area is calculated as per the following relation [25]

$$
A_{t h}=\frac{\hat{v}}{q_{e q}} \times H_{a}, \mathrm{~mm}^{2}
$$


where $\hat{v}$ is the specific volume of weld metal in $\mathrm{mm}^{3} / \mathrm{gram}, q_{e q}$ is the heat required to melt a unit mass of metal, and $H_{a}$ is the heat input per unit length in $\mathrm{J} / \mathrm{mm}$. The $q_{e q}$ for AC square-waveform welding of 2.25Cr-1 Mo heat-resistant steel is obtained from the literature [18].

\subsubsection{Performance measure of $\mathrm{V}$-groove welding}

The performance measure in the $\mathrm{V}$-groove welding was the deposition rate measured from the cross-sectional area of the bead using the macrograph, as shown in Fig. 4. The following expression gives the deposition rate.

$$
D R_{v}=\frac{A_{d}}{n_{p}} S \rho \frac{g}{\min }
$$

where $A_{d}$ is the deposited area, $\mathrm{S}$ is the welding speed in $\mathrm{cm} / \mathrm{min}, n_{p}$ is the number of layers, and $\rho$ is the density of the electrode wire in $\mathrm{g} / \mathrm{mm}^{3}$. The measured values of the deposition rate for the base and high deposit conditions are obtained 134.66 and $178.35 \mathrm{~g} / \mathrm{min}$.

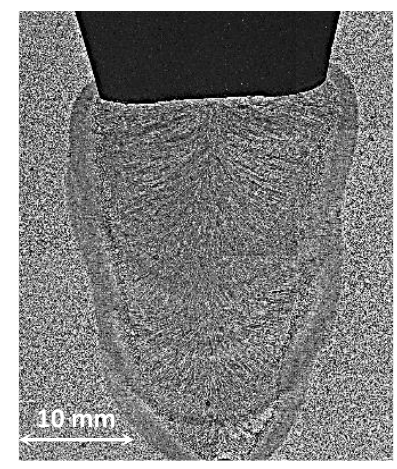

Figure 4. Macrograph of V-groove weld.

\section{Approach for process map development}

The process map is developed in sequential steps. Firstly, process models for bead-on-plate welds are developed and validated. Once the applicability of bead-on-plate results to the V-groove condition is established, multi-criteria optimization is conducted, and the process map is developed. The responses from bead-on-plate experiments, namely, penetration $(P)$, bay area $(A b)$, deposition rate $(D R)$, melting efficiency $\left(\eta_{m}\right)$, dilution, heat input $(H I)$, and flux-wire ratio $(F W R)$, are used to determine the quality of the weld. The frequency $(F)$, EN ratio $(E)$, current $(I)$, and welding speed $(S)$ were used as the process variable to build the mathematical relation. The regression coefficients are obtained using stepwise regression and setting the value of $\alpha$ at 0.15 , with a confidence interval of $95 \%$. Details of the stepwise regression method for welding application can be found elsewhere [11]. In the present investigation, multi-criteria optimization of different responses such as melting efficiency, bead feature, and production rate is performed using the weighted aggregate quality index (AQI) technique. The weighted aggregate quality index is a technique that converts multiple responses into a single response to obtain the best optimal solution. The AQI is given as follows [26]:

$$
I_{i, n}=\left(1-n+n \sum_{j=1}^{n} w_{i} S_{i j}{ }^{-\frac{1}{k}}\right)^{-k}
$$

An optimal value of $\mathrm{k}$ as 0.4 avoids insensitiveness issues. The weights are obtained from the number of criteria $(n)$ as follows:

$$
w_{i}=\frac{1}{n}
$$

The heat input and flux-wire ratio are taken as the constraints, whereas the process variablesfrequency, current, EN ratio, and welding speed-are considered as the bounds. The constraints and bounds for multi-criteria optimization for a bead-on-plate weldment are given as follows:

Objective function: maximize $I_{i, 5}$;

Subject to constraint: $2 \leq H I \leq 3.5,0.6 \leq F W R \leq 1.2$;

Bounds: $20 \leq F \leq 80,0.25 \leq E \leq 0.75,400 \leq I \leq 700,20 \leq S \leq 50$.

The optimization exercise is conducted using the generalized reduced gradient (GRG) method available in the 'Microsoft Excel Solver' to achieve maximum AQI. The attributes of GRG methods are set as a convergence: $10^{-4}$ and population size: 100 . The maximum and minimum value of penetration, bay area, deposition rate, melting efficiency, and dilution were obtained for the given range of process parameters $(9.59 \mathrm{~mm}, 2.35 \mathrm{~mm}),\left(124.94 \mathrm{~mm}^{2},-1.30 \mathrm{~mm}^{2}\right),(197.92 \mathrm{~g} / \mathrm{min}, 55.20 \mathrm{~g} / \mathrm{min})$, 
$(100.00 \%, 41.54 \%)$, and $(69.27 \%, 38.15 \%)$, respectively. The purpose of the V-groove weldment design is to obtain the process parameters that can deposit each layer in one pass with maximum deposition subjected to the constraints and bounds described as follows:

Objective function: maximize $D R_{v}$;

Subject to constraint $W \geq 20 \mathrm{~mm}, A_{r}=28 \mathrm{~mm}^{2}, H I \leq 4 \frac{\mathrm{kJ}}{\mathrm{m}^{\prime}}$;

Bounds $20 \leq F \leq 80,0.25 \leq E \leq 0.75,400 \leq I \leq 700,20 \leq S \leq 50$.

\section{Results and discussion}

\subsection{Process models}

The models for different process outcomes are obtained using the stepwise regression method described in the earlier section. The regression models are as follows:

$$
\begin{aligned}
& P=3.001-1.948 F-0.23 E+6.265 I+1.431 S+2.276 F^{2}-1.94 E I-1.782 I S \\
& A_{b}=-12.6 \mathrm{~F}+1.5 \mathrm{E}+124.9 \mathrm{I}+15.96 \mathrm{~S}+30.6 \mathrm{~F}^{2}-25 \mathrm{FI}-23.9 \mathrm{EI}-76.5 \mathrm{IS} \\
& D R=65.3-28.19 F+23.84 E+95.5 I+11.9 S+19.67 F^{2}+13.28 I^{2}-44.75 I S \\
& \eta_{m}=51.77+9.97 F-6.19 E+14.71 I+10.42 S+11.89 E^{2}+9.86 I^{2}-25.9 F E+16.09 E S(13) \\
& \% \text { Dilution }=45.78+8.89 F-7.63 E+14.78 I+14.72 S-8.44 F^{2}-8.49 I^{2} \\
& H I=3.899+0.0687 F-0.043 E+2.542 I-5.42 S+3.028 S^{2}-1.441 I S \\
& F W R=1.688+0.51 F-0.442 E-0.859 I-0.833 S-0.483 F^{2}+0.52 E S+0.58 I S \\
& W=22.84+2.33 F-5.04 E+21.97 I-10.67 S-6.63 I^{2}-5.12 F I+7.02 E S-8.15 I S \\
& A_{r}=39.93+18.96 F+33.05 E+39.4 I-85.4 S+27.3 I^{2}+56.4 S^{2}-35.8 F E-46.4 I S
\end{aligned}
$$

The models are functions of linear, quadratic, or interaction terms of process parameters. Most of the process outcomes have current as the quadratic term that shows the significance of the welding current in influencing the process. Other process parameters appear primarily appear as linear or interaction terms. Once validated for their accuracy, the models can be used to understand their relative influence on the process outcomes. The fit and accuracy of the models are evaluated through ANOVA and comparison of actual and predicted data. The results of the ANOVA are shown in Table 3. Since the average percentage prediction error in the response is significantly less, the models are good fits. In Fig. 5, the predicted values agree with the measured value for the data used for the developing model and the data used to confirm the model.

Table 3. Model validation results from ANOVA.

\begin{tabular}{cccccccccc}
\hline \multirow{2}{*}{ Responses } & \multicolumn{3}{c}{ Regression } & \multicolumn{3}{c}{ Residual error terms } & \multicolumn{3}{c}{ Model features } \\
\cline { 2 - 11 } & SS & DF & MS & SS & DF & MS & F-ratio & P & $\mathbf{R}^{\mathbf{2}} \mathbf{( \% )}$ \\
\hline Penetration & 51.951 & 7 & 7.4216 & 1.6957 & 13 & 0.1304 & 56.90 & 0.00 & 96.84 \\
\hline Bead width & 525.97 & 8 & 65.74 & 10.058 & 12 & 0.83 & 78.44 & 0.00 & 98.12 \\
\hline Bay area & 61483.8 & 8 & 7685.5 & 642.7 & 13 & 49.4 & 155.46 & 0.00 & 98.97 \\
\hline Reinforcement area & 13325.7 & 8 & 1665.72 & 296.1 & 12 & 24.67 & 67.52 & 0.00 & 97.83 \\
\hline Deposition rate & 21339.3 & 7 & 3048.47 & 187.9 & 13 & 14.45 & 210.93 & 0.00 & 99.13 \\
\hline Melting efficiency & 2280.95 & 8 & 285.119 & 58.45 & 12 & 4.87 & 58.54 & 0.00 & 97.50 \\
\hline Percentage dilution & 651.24 & 6 & 108.541 & 71.42 & 14 & 5.101 & 21.28 & 0.00 & 90.12 \\
\hline Heat input & 32.7844 & 6 & 5.4641 & 0.1253 & 14 & 0.00895 & 610.37 & 0.00 & 99.62 \\
\hline Flux-wire ratio & 1.1286 & 7 & 0.1612 & 0.1628 & 13 & 0.01252 & 12.87 & 0.00 & 87.39 \\
\hline
\end{tabular}




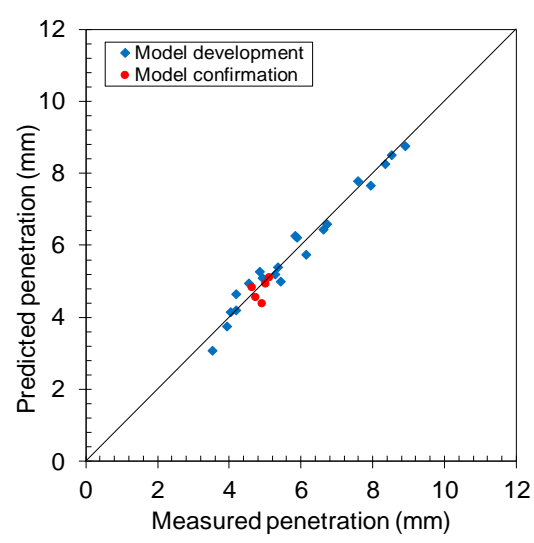

(a)

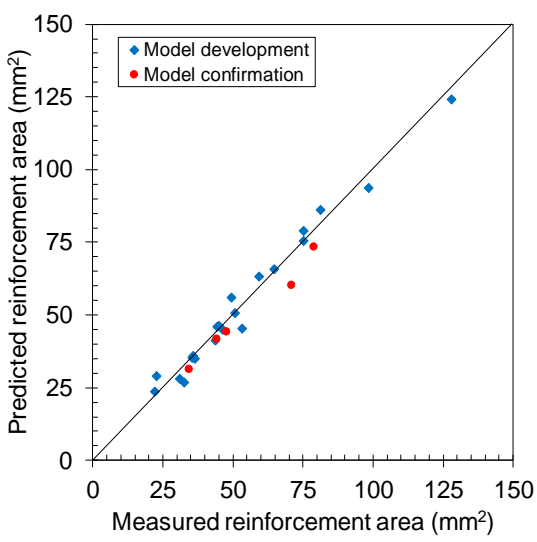

(d)

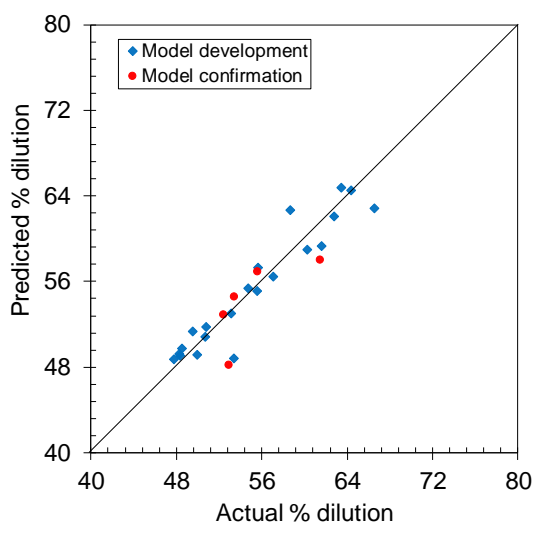

(g)

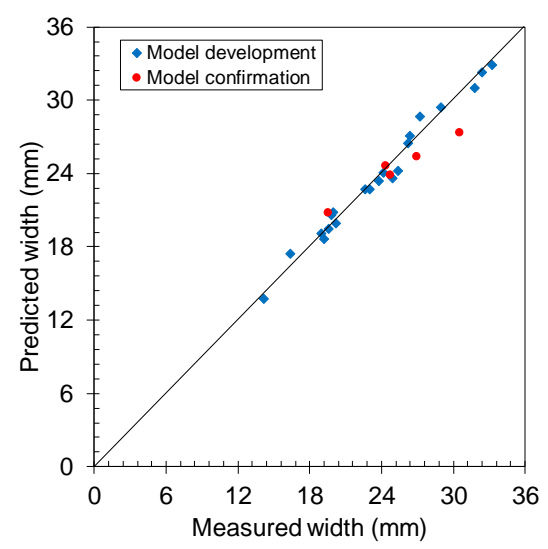

(b)

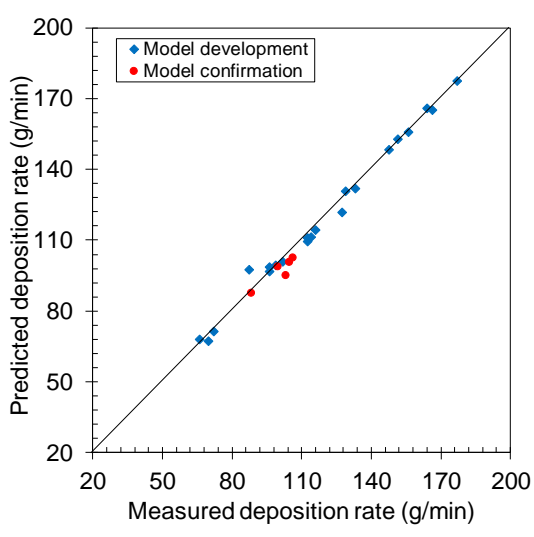

(e)

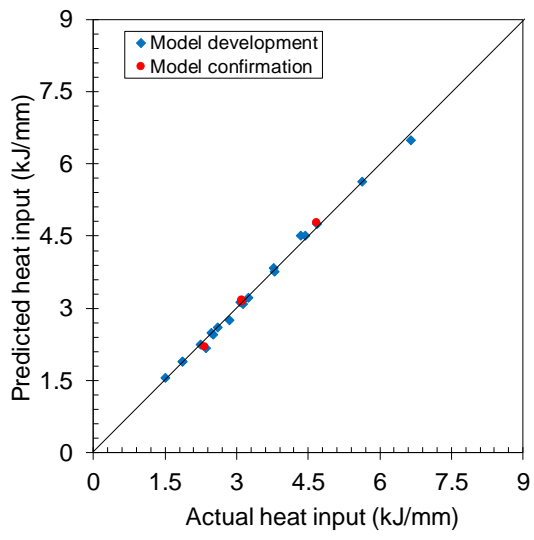

(h)

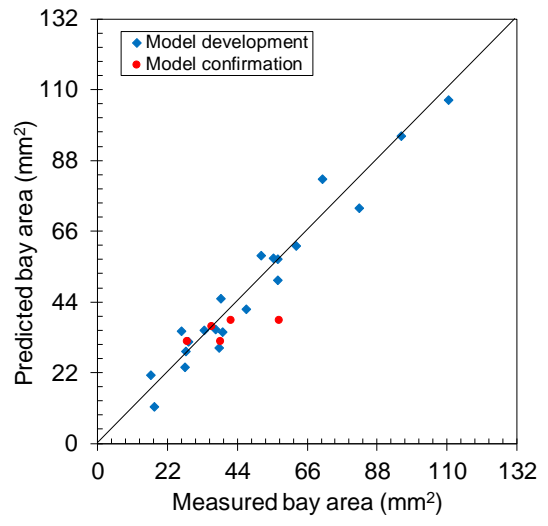

(c)

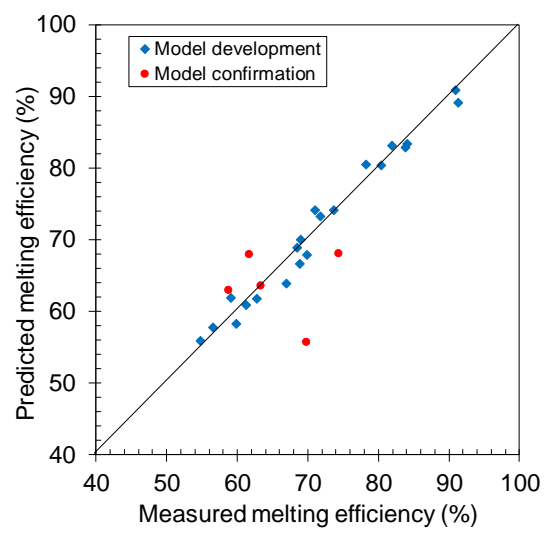

(f)

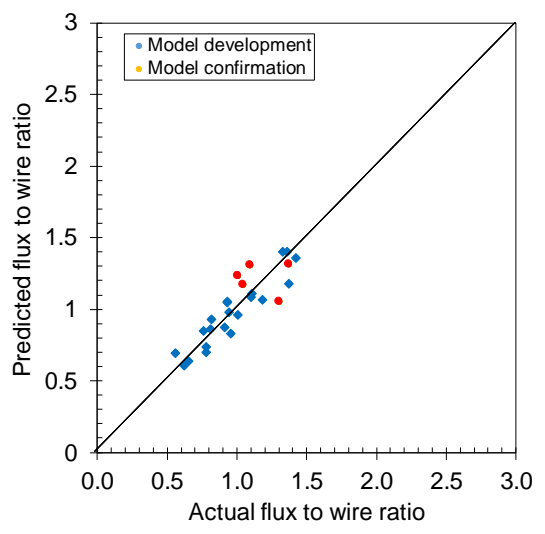

(i)

Figure 5. Comparison between predicted and measured value of (a) penetration, (b) bead width, (c) bay area, (d) reinforcement area, (e) deposition rate, (f) melting efficiency, (g) \% dilution, (h) heat input, and (i) flux-wire ratio.

\subsection{Parametric effects}

The welding parameters' effect on the process outcomes is shown in Fig. 6. The current is the most influencing among the four welding parameters, followed by welding speed and EN ratio. The welding current and the speed determine the amount of heat supplied to the workpiece (Fig. 6a), and likewise in the conventional direct current submerged arc welding. The welding current affects all the process outcomes (Fig. 6b-g). The current directly influences the electrode melting to increase the deposition rate (Fig. 6b). The welding current causes the pinch effect on the electrode tip, and the droplets impinge with more force and energy when the welding current is increased. As a result, the current increase causes an increase in penetration and dilution (Fig. 6c and d). 


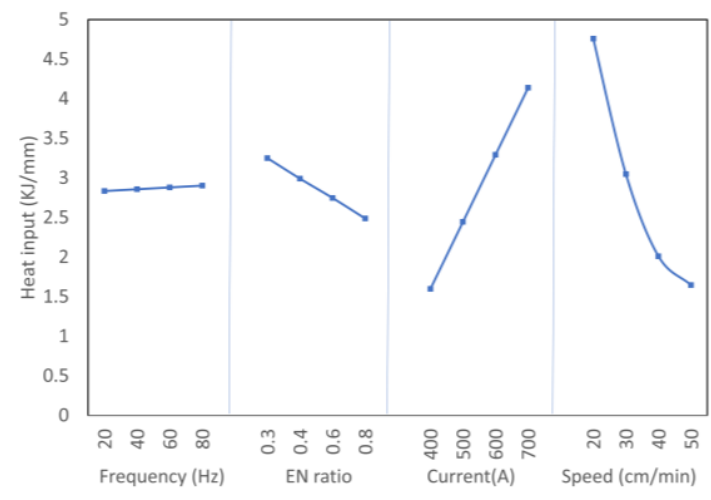

(a)

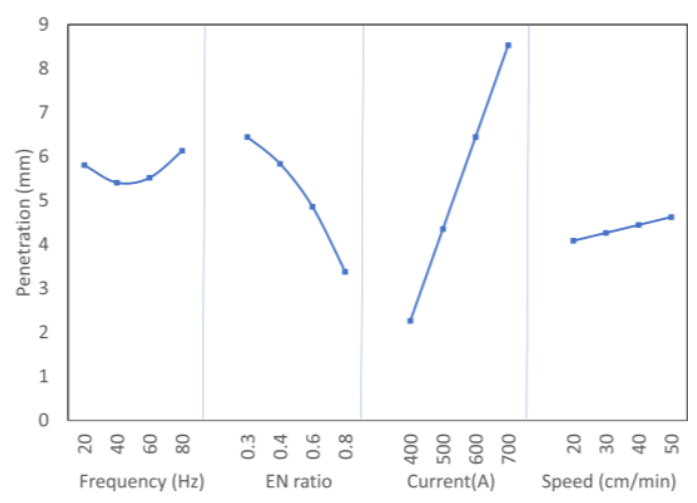

(c)

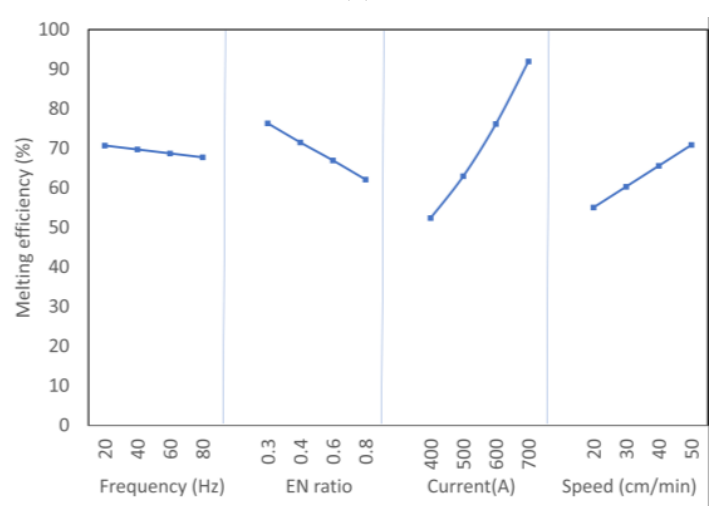

(e)

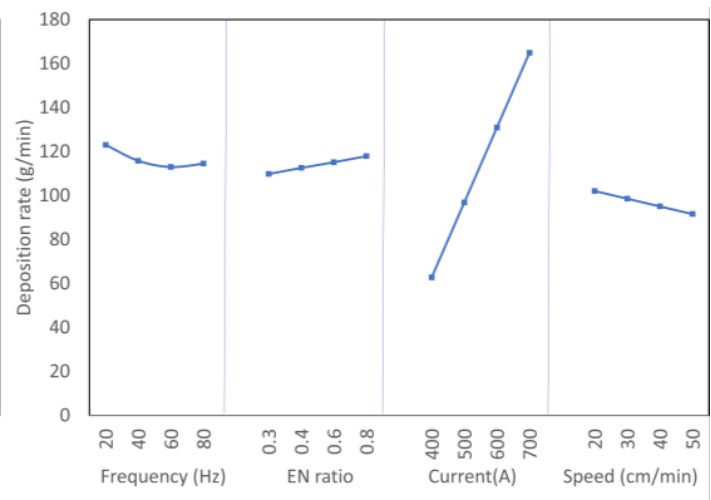

(b)

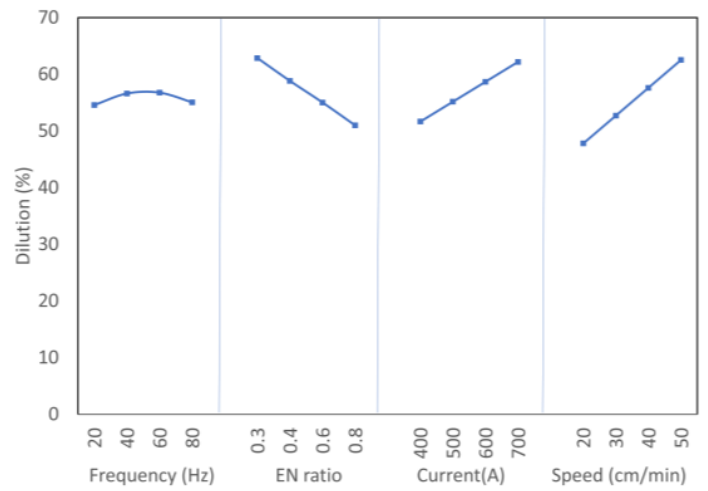

(d)

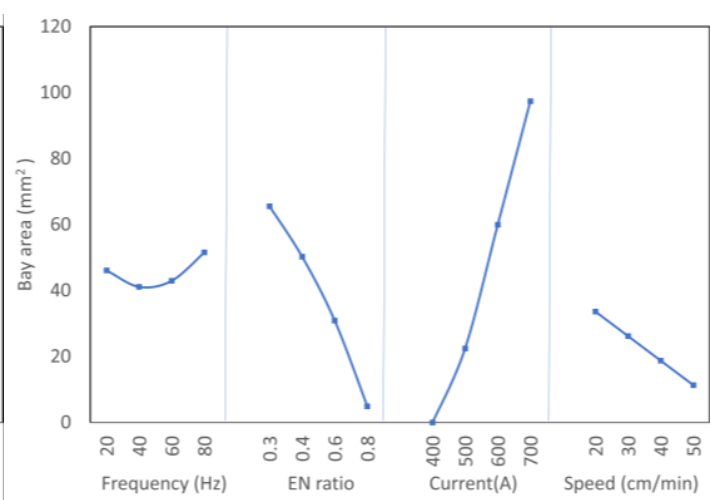

(f)

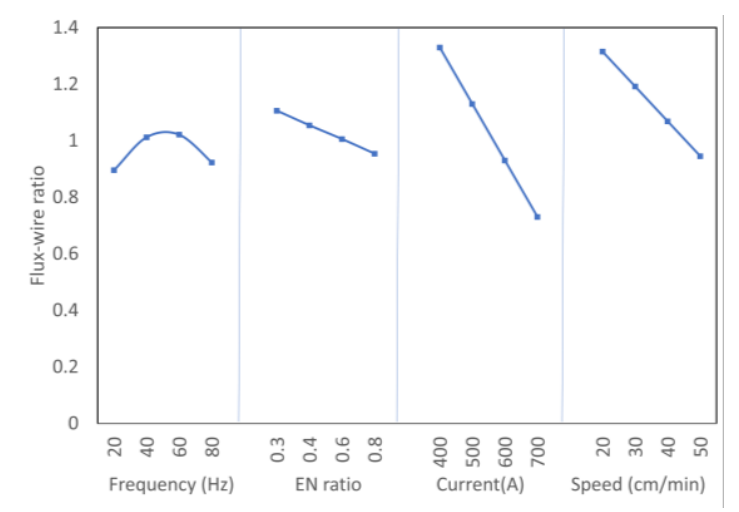

(g)

Figure 6. Parametric effects on (a) heat input, (b) deposition rate, (c) penetration, (d) \% dilution, (e) melting efficiency, (f) bay area, and (g) flux-wire ratio.

The current increase also positively affects melting efficiency and the flux-wire ratio (Fig. 6e and $\mathrm{f}$ ). Deeper penetration and enhanced dilution caused by an increase in current melt more 
amount of base metal and electrode than the flux leads to a reduction in the flux-wire ratio. The only adverse effect of the welding current is an increase in the bay area (Fig. $6 \mathrm{~g}$ ). The increase in current causes a deeper penetration in the positive part of the current cycle while the negative part increases the lateral spread of the molten material. As a result, the conditions are favorable for the growth of the bay area. The conflicting effects, i.e., favorable and unfavorable (e.g., increase in the bay area), suggest that the most favorable current value may lie between the limiting values. This is a classic case of process optimization due to contradictory objectives, as dealt with in the subsequent section. The welding speed directly influences the heat supplied to the base metal. The deposition rate is not much affected by the welding speed, as the electrode melting rate is almost independent of the welding speed. At higher welding speeds, the interaction between the arc and base plate is a shorter duration, which causes a slight decline in electrode melting and deposition rate (Fig. 6b). However, the welding speed determines the volumetric heating of the base material and the spreading of the molten metal. Consequently, effects of welding speed on flux-wire ratio can be observed (Fig. 6g). The volumetric heating also influences other responses, such as bay area, dilution, and melting efficiency.

Contrary to the conventional SAW, the penetration is less affected by the welding speed, which agrees with the previous results on square waveform SAW. The square form welding can maintain the penetration at higher speeds [18]. The increase in the EN ratio brings in the same changes observed when polarity changes from direct positive to direct negative, such as increased deposition rate and decrease in penetration, dilution, and melting efficiency. However, the choice of the EN ratio gives an additional controllable process parameter to design a desired process and product, as explained for the V-groove case in the subsequent section. The frequency has a minor effect on the process outcomes. Higher frequency, such as $80 \mathrm{~Hz}$, induces a stiffness to the arc that helps in increasing the penetration (Fig. 6 c) and reducing the flux-wire ratio (Fig. 6 g).

The relative influence of the parameters over the entire range of investigation can be visualized with sensitivity analysis. Mathematically, sensitivity is defined as the partial derivative of the response $(y)$ with respect to its process variables $(x)$, i.e., $\frac{\partial y}{\partial x}$. To compare the influences of the different parameters on a common scale, the response and input variables are normalized between 0 and 1 . Further to evaluate the influence of input parameters over the entire domain, root mean square sensitivity is used, i.e., square root of sum square of point sensitivities. The results of sensitivity analysis are summarized in Fig. 7 .

The process is more sensitive towards the change in welding current and welding speed (Fig. 7a). The welding current influences all the process responses, and so does the welding speed, except for deposition rate and penetration, reasons for which are explained earlier. Similarly, Fig. 7b generalizes the influence of EN ratio and frequency, as observed in Fig. 6. Both have some minor influence on dilution, penetration, flux-wire ratio, and melting efficiency.

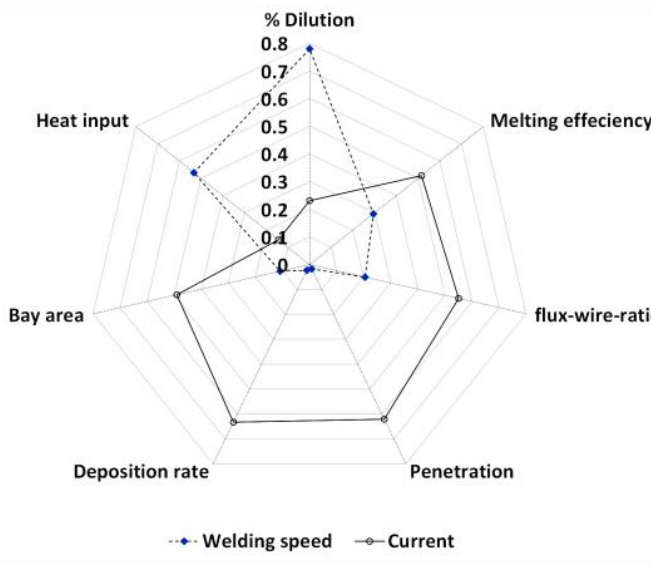

(a)

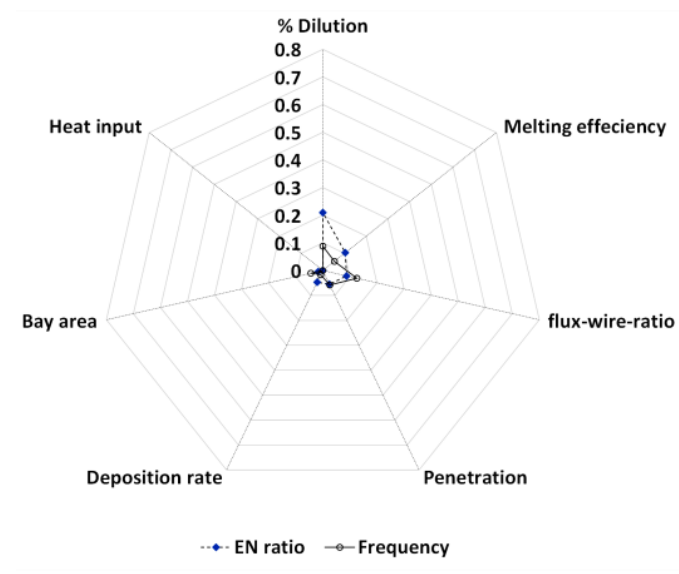

(b)

Figure 7. Variation in root mean square sensitivity: (a) major influence, (b) minor influence. 
The welding is a multi-variate complex process. Typical optimization investigations, as reported, give a unique set of optimized parameters which are merely mathematical outcomes but practically almost impossible to replicate. The optimization of any actual process results in a set of several optimal or near-optimal solutions (i.e., process map) that are practically as good as mathematically obtained a unique set (if possible to achieve). In recent times, the optimization investigations are presented with the process maps [22] rather than the unique set of optimized parameters.

\subsubsection{Process map for bead-on-plate weld}

The AQI represents the combined goodness of the responses. For the development of a process map, the contours of AQI are plotted against the process constraints, i.e., flux-wire ratio and heat input in Fig. 8.
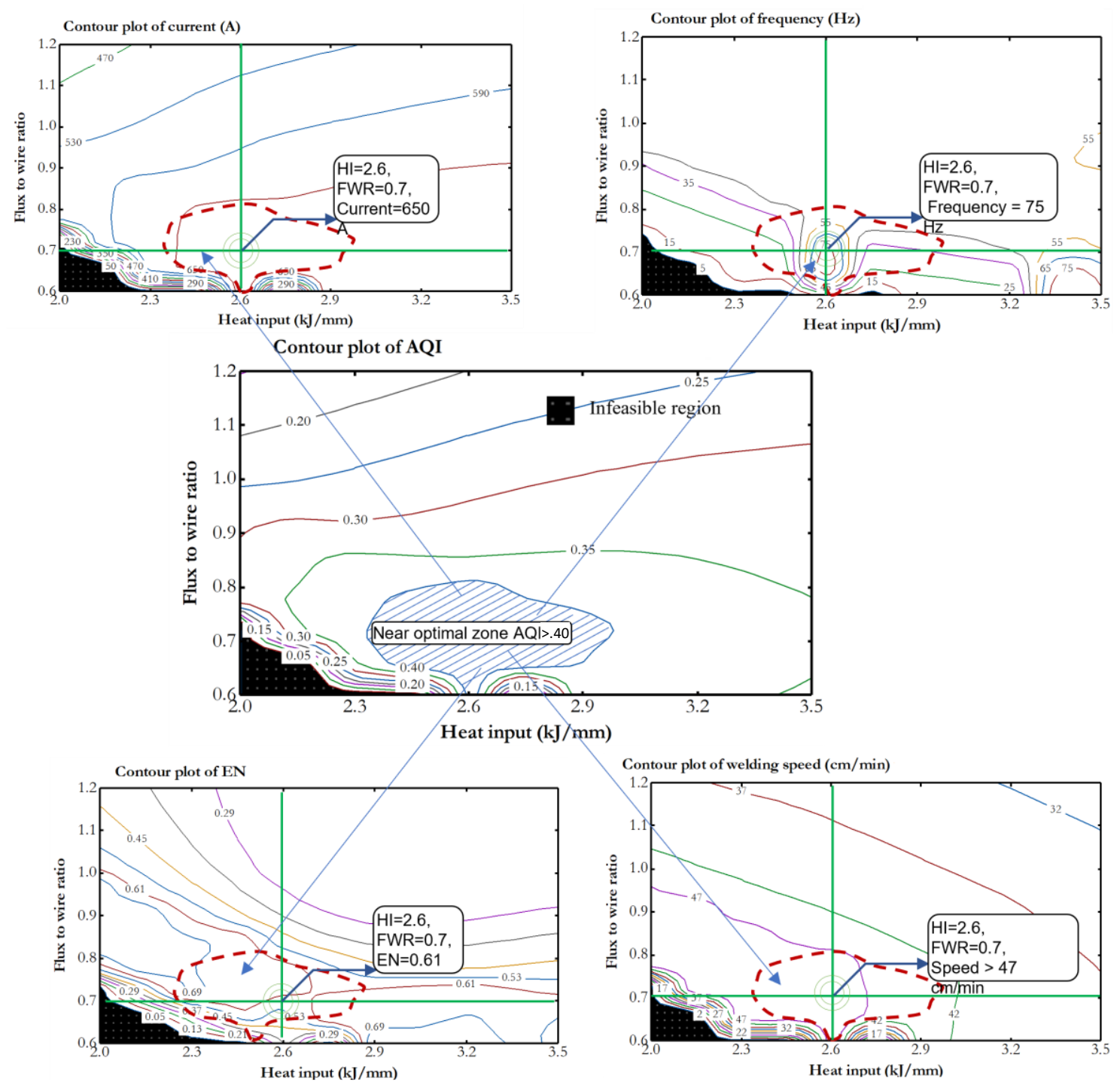

Figure 8. Process map for bead-on-plate welds.

The maximum AQI is around 0.40 obtained for several combinations of flux-wire ratio and heat input. Therefore, the optimal (or near-optimal) process conditions can be achieved for several sets of process conditions. For the desired values of flux-wire ratio and heat input, the best quality (i.e., AQI $>0.40$ ) can be achieved for the corresponding values of the process parameters. For example, a flux-wire ratio around 0.7 and heat input of $2.6 \mathrm{~kJ} / \mathrm{mm}$ (Fig. 8) corresponds to frequency $\approx 75$ $\mathrm{Hz}$, EN ratio $\approx 0.6$, current $\approx 650 \mathrm{~A}$ ), and welding speed $\approx 47 \mathrm{~cm} / \mathrm{min}$. The optimal solution space for the process map shows that the process is more sensitive towards the change in current and speed compared to the frequency and EN ratio, vis à vis a slight change in current and speed would bring down the AQI from 0.4, while the same would not be with the frequency and EN ratio. 
The objective of V-groove welding is to attain the maximum deposition rate under the constraints, as explained earlier. The deposition rate of $\mathrm{V}$-groove welding was measured from the crosssectional area in both base and high deposit conditions. The deposition rate model equation (i.e., Eq. 12) of bead-on-plate welding is compared with the V-groove welding technique. The mean absolute percentage error (MAPE) value, in both base and high deposit conditions, does not exceed $3 \%$, which indicates that the process models of bead-on-plate are suitable for groove weld application.

For the case of V-groove welds, Fig. 9 shows the feasible contour bands for (9a) objective (i.e., deposition rate) and process conditions (9b) frequency, (9c) EN ratio, (9d) current, and (9e) welding speed against bead width, reinforcement area, and heat input.

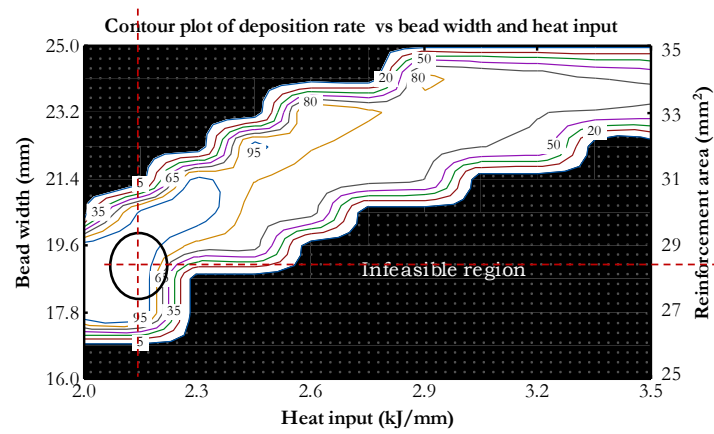

(a)

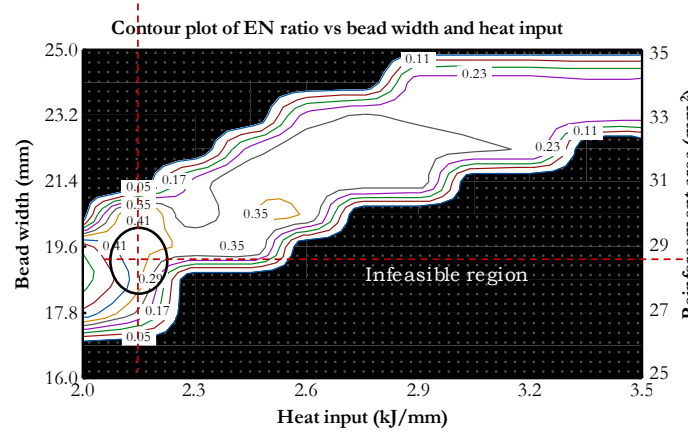

(c)

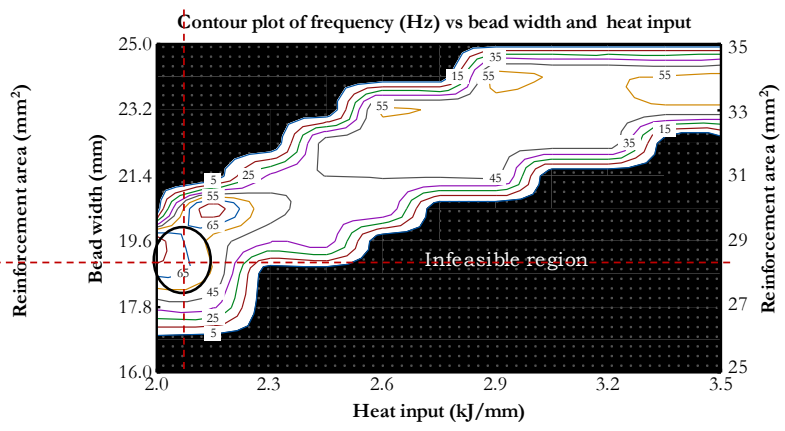

(b)

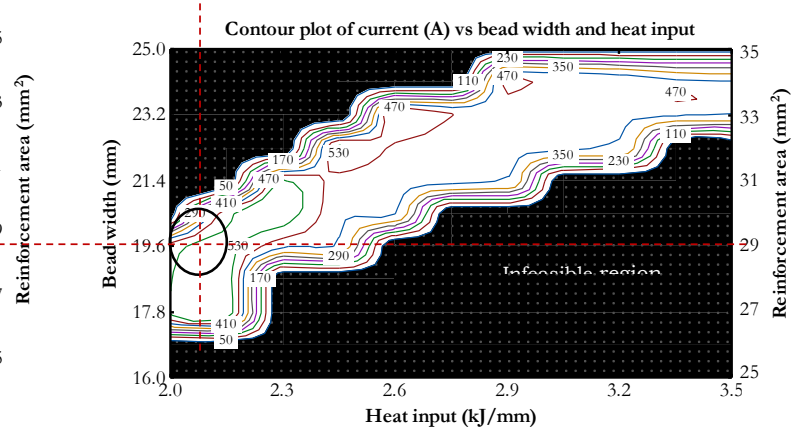

(d)

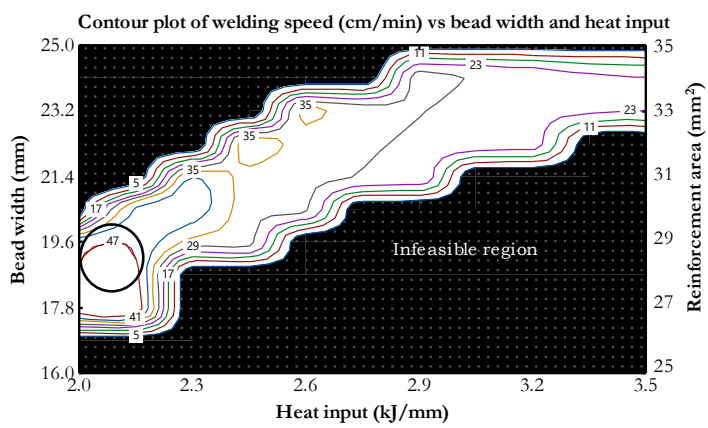

(e)

Figure 9. Process map for V-groove welds: (a) deposition rate, (b) frequency, (c) EN ratio, (d) current, and (e) welding speed with respect to heat input, bead width, and reinforcement height.

The region of optimal deposition rate shown in Fig. 9(a) indicates that the maximum deposition rate is around $95 \mathrm{~g} / \mathrm{min}$, and the corresponding bead width, reinforcement area, and heat input are $18.7 \mathrm{~mm}, 28 \mathrm{~mm}^{2}$, and $2.15 \mathrm{~kJ} / \mathrm{mm}$, respectively. The optimal process parameters from Fig. 9 (be) are $52.85 \mathrm{~Hz}, 0.37,562.48 \mathrm{~A}$, and $48.27 \mathrm{~cm} / \mathrm{min}$. The maximum deposition rate obtained without constraint was $105.41 \mathrm{~g} / \mathrm{min}$; however, the constraint on heat input and reinforcement restricts the maximum deposition rate. Nevertheless, the results are remarkable since $90 \%$ of the maximum deposition rate possible for V-groove weld is reached, even by following the heat input, width, and deposition area constraints.

The solution space of the process map is narrower in the V-groove weld than for the bead-onplate welds. The reason is that in the case of V-groove welding, the single objective function is 
considered. On the other hand, bead-on-plate weldment has multiple objectives that widen the solution space. Compared to the bead-on-plate, the one-pass-each-layer V-groove weld with the constraints can be achieved at about $70 \%$ of the base deposition rate ( $95 \mathrm{vs} 134.66 \mathrm{~g} / \mathrm{min}$ ). The reduction in the deposition rate is compensated by the reduction in the amount of weld metal obtained with one-pass V-groove welds. On the other hand, reducing the number of passes with one-pass onelayer V-groove welds considerably reduces the production time and cost.

The present investigation presents a new approach for process map development of V-groove welding for the AC square-waveform SAW process. The viability of multiple responses, such as penetration, bay area, deposition rate, percentage dilution, heat input, and flux-wire ratio, is analyzed over various process variables, such as current, EN ratio, welding speed, and frequency. This work is not limited to only the SAW process but can be extended to other arc-welding processes and any multi-variable manufacturing process. The future work can also consider other additional process variables, such as the contact tip to work distance, the height of the flux layer, voltage, wire diameter, flux composition, and the torch angle.

\section{Conclusions}

This study discloses the development of new process maps for depositing V-groove welds using the concept of bead-on-plate welding. The proposed approach is implemented on heat-resistant steel as candidate material. The major conclusions of the investigation are as follows:

1. The investigation offers a unique method for developing a process map for one-pass-each-layer V-groove welds without depositing many V-groove welds, which are time-, material-, and costconsuming. The results obtained with the bead-on-plate welds are good enough to develop a process map for a V-groove weld for the candidate material and the process studied in this investigation, i.e., square-waveform submerged arc welding of heat-resistant steel. The process map development is a generic approach that can be implemented to other materials and other welding techniques.

2. The closeness of the predicted and experimental results evidences the validity of the proposed approach. The bead-on-plate process model of deposition rate experimentally achieved in onepass-each-layer V-groove weld differs within 3\%.

3. By adopting a comprehensive design of experiment and process map development, the investigation reveals that $90 \%$ of the maximum deposition rate possible for one-pass-each-layer Vgroove welds within the constraints of heat input and weld applied in this investigation. The one-pass-each-layer V-groove weld with the constraints can be achieved at about $70 \%$ of the base deposition rate achieved in the bead-on-plate condition. The reduction in the number of passes and associated production cost and time with one-layer one-pass V-groove weld outperforms the reduction in the deposition rate.

4. The parametric study of process parameters on the response suggests that an increase in welding current causes an increase in all the responses, namely, penetration, bay area, deposition rate, melting efficiency, heat input, flux-wire ratio, and \% dilution, which is good except for the flux-wire ratio. On the other hand, the welding speed has mixed responses. The heat input and flux-to-wire ratio drastically reduce with the welding speed increase while dilution and meting efficiency increase. Changes in the welding speed less influence penetration and the deposition rate.

5. The sensitivity analysis, which provides a global view of the influence of process parameters, indicates that square-waveform submerged arc welding is more sensitive towards change in current and welding speed than frequency and EN ratio; however, all the process parameters have a role in process optimization. Although the EN ratio and frequency have a minor influence on process responses, they help in fine-tuning to achieve optimal results.

Conflicts of Interest: The authors declare no conflicts of interest.

Acknowledgements: The authors acknowledge the joint research agreement between KU Leuven and the Joining and Welding Research Institute (JWRI), Osaka University, Japan, that facilitated numerical modeling and analysis. The experimental support provided under the joint project between Hitachi Zosen Corporation, Indian Institute of Technology Hyderabad, India, and JWRI, Osaka, Japan, under the Globalizing Asian Networks Project (Ja19990018), is acknowledged. 
1. Pedrazzo, G., C. A. Barone, and G. Rutili. "AC/DC generators with waveform control: innovation in submerged arc welding." Weld. Int. 23, no. 11 (2009): 839-845.

2. Pouraliakbar, H., G. Khalaj, M. R. Jandaghi, and M. J. Khalaj. "Study on the correlation of toughness with chemical composition and tensile test results in microalloyed API pipeline steels." J. Min. Metall., Sect. B Metall. 51, no. 2 (2015): 173-178.

3. Ansaripour, Navid, Ali Heidari, and Seyed Ali Eftekhari. "Multi-objective optimization of residual stresses and distortion in submerged arc welding process using genetic algorithm and harmony search." Proc. Inst. Mech. Eng. C J Mech. Eng. Sci. 234, no. 4 (2020): 862-871.

4. Choudhary, Ankush, Manoj Kumar, Munish Kumar Gupta, Deepak Kumar Unune, and Mozammel Mia. "Mathematical modeling and intelligent optimization of submerged arc welding process parameters using hybrid PSO-GA evolutionary algorithms." Neural. Comput. Appl. 32, no. 10 (2020): 5761-5774.

5. Sharma, Abhay. "A comparative study on mechanical properties of single-and twin-wire welded joints through multi-objective meta-heuristic optimization." Int. J. Manuf. Res 11, no. 4 (2016): 374-393.

6. Saini, Vijay, and Shivali Singla. "Parameter Optimization of SAW in Hardfacing Process Using Hybrid Approach of Adaptive Stimulated Annealing and Neural Networks." Asian J. Eng. Appl. Technol. 1, no. 2 (2012): 16-20.

7. Vedrtnam, Ajitanshu, Gyanendra Singh, and Ankit Kumar. "Optimizing submerged arc welding using response surface methodology, regression analysis, and genetic algorithm." Def. Technol. 14, no. 3 (2018): 204-212.

8. Sarkar, Abhijit, Arindam Majumder, Martand Pawar, S. C. Saha, and R. N. Rai. "Optimization of process parameters of submerged arc welding by using grey-fuzzy-based Taguchi method for AISI 1518 grade steel." Proc. Inst. Mech. Eng. B J Eng. Manuf. 228, no. 11 (2014): 1491-1500.

9. Sharma, Abhay, Navneet Arora, and Bhanu K. Mishra. "Mathematical model of bead profile in high deposition welds." J. Mater. Process. Technol. 220 (2015): 65-75.

10. Chakrabarti, R., Roy, J., Biswas, P., \& Saha, S. C. (2021). Influence of Microstructural Changes on Residual Stress Characteristics and Macro-Hardness of Submerged Arc Welded P-91 Steel Plates. Soldag. e Inspecao, 26.

11. Sharma, A., Arora, N., \& Mishra, B. K. (2009). Statistical modeling of deposition rate in twin-wire submerged arc welding. Proc. Inst. Mech. Eng. B J Eng. Manuf., 223(7), 851-863.

12. Zhang, J., Coetsee, T., Dong, H., \& Wang, C. (2020). Fine-Tuned Element Transfer Strategies for Ternary CaF 2-SiO 2-CaO Fluxes in Submerged Arc Welding: An Environmentally Friendly Approach. Metall. Mater. Trans. B, 51(4), 1350-1354.

13. Sharma, A. (2016). A comparative study on mechanical properties of single-and twin-wire welded joints through multi-objective meta-heuristic optimization. Int. J. Manuf. Res., 11(4), 374-393.

14. Komen, Hisaya, Masaya Shigeta, Manabu Tanaka, Yohei Abe, Takahiro Fujimoto, Mitsuyoshi Nakatani, and Anthony B. Murphy. "Numerical Investigation of Heat Transfer During Submerged Arc Welding Phenomena by Coupled DEM-ISPH Simulation." Int. J. Heat Mass Transf. 171 (2021): 121062.

15. Sharma, Abhay, Navneet Arora, and Bhanu K. Mishra. "Predictive modelling and sensitivity analysis of flux consumption rate in twin-wire submerged arc welding." J. Manuf. Technol. Res. 1, no. 3-4 (2009): 287-303.

16. Jindal, Sandeep; Chhibber, Rahul; Mehta, N. P. “Investigation on flux design for submerged arc welding of high-strength lowalloy steel." Proc. Inst. Mech. Eng. B J Eng. Manuf. 227, no. 3(2013), 383-395

17. Sharma, Abhay, Navneet Arora, and S. R. Gupta. "Investigation into arc behavior during twin-wire submerged arc welding." Mater. Manuf. Process. 25, no. 8 (2010): 873-879.

18. Mohanty, Uttam Kumar, Yohei Abe, Takahiro Fujimoto, Mitsuyoshi Nakatani, Akikazu Kitagawa, Manabu Tanaka, Tetsuo Suga, and Abhay Sharma. "Performance evaluation of alternating current square waveform submerged arc welding as a candidate for fabrication of thick welds in 2.25 Cr-1Mo heat-resistant steel." J. Press. Vessel Technol. 142, no. 4 (2020): 041506.

19. Mohanty, Uttam Kumar, Abhay Sharma, Mitsuyoshi Nakatani, Akikazu Kitagawa, Manabu Tanaka, and Tetsuo Suga. "A semianalytical nonlinear regression approach for weld profile prediction: a case of alternating current square waveform submerged arc welding of heat resistant steel." J. Manuf. Sci. Eng. Trans. ASME 140, no. 11 (2018): 111013.

20. He, Kuanfang, Jigang Wu, and Guangbin Wang. "Time-Frequency Entropy Analysis of Alternating Current Square Wave Current Signal in Submerged Arc Welding." J. Comput. 6, no. 10 (2011): 2092-2097.

21. Mohanty, Uttam Kumar, Abhay Sharma, Yohei Abe, Takahiro Fujimoto, Mitsuyoshi Nakatani, Akikazu Kitagawa, Manabu Tanaka, and Tetsuo Suga. "Thermal modelling of alternating current square waveform arc welding." Case Stud. Therm. Eng. 25 (2021): 100885.

22. Sharma, Abhay. "A fundamental study on qualitatively viable sustainable welding process maps." J. Manuf. Syst. 46 (2018): 221230 .

23. Mohanty, U. K., \& Sharma, A. (2021). Recent developments in AC square waveform welding. Materials Today: Proceedings, 45, 5709-5713.

24. Choudhury, Sanatan, Abhay Sharma, Uttam Kumar Mohanty, Ryu Kasai, Masaharu Komura, Manabu Tanaka, and Tetsuo Suga. "Mathematical model of complex weld penetration profile: A case of square AC waveform arc welding." J. Manuf. Process. 30 (2017): 483-491.

25. Chandel, R. S. "Electrode melting and plate melting efficiencies of submerged arc welding and gas metal arc welding." J. Mater. Sci. Techno. 6, no. 8 (1990): 772-777.

26. Swamee, Prabhata K., and Aditya Tyagi. "Describing water quality with aggregate index." J. Environ. Eng. 126, no. 5 (2000): 451455. 
Appendix 1: Experimental results of bead-on-plate welding.

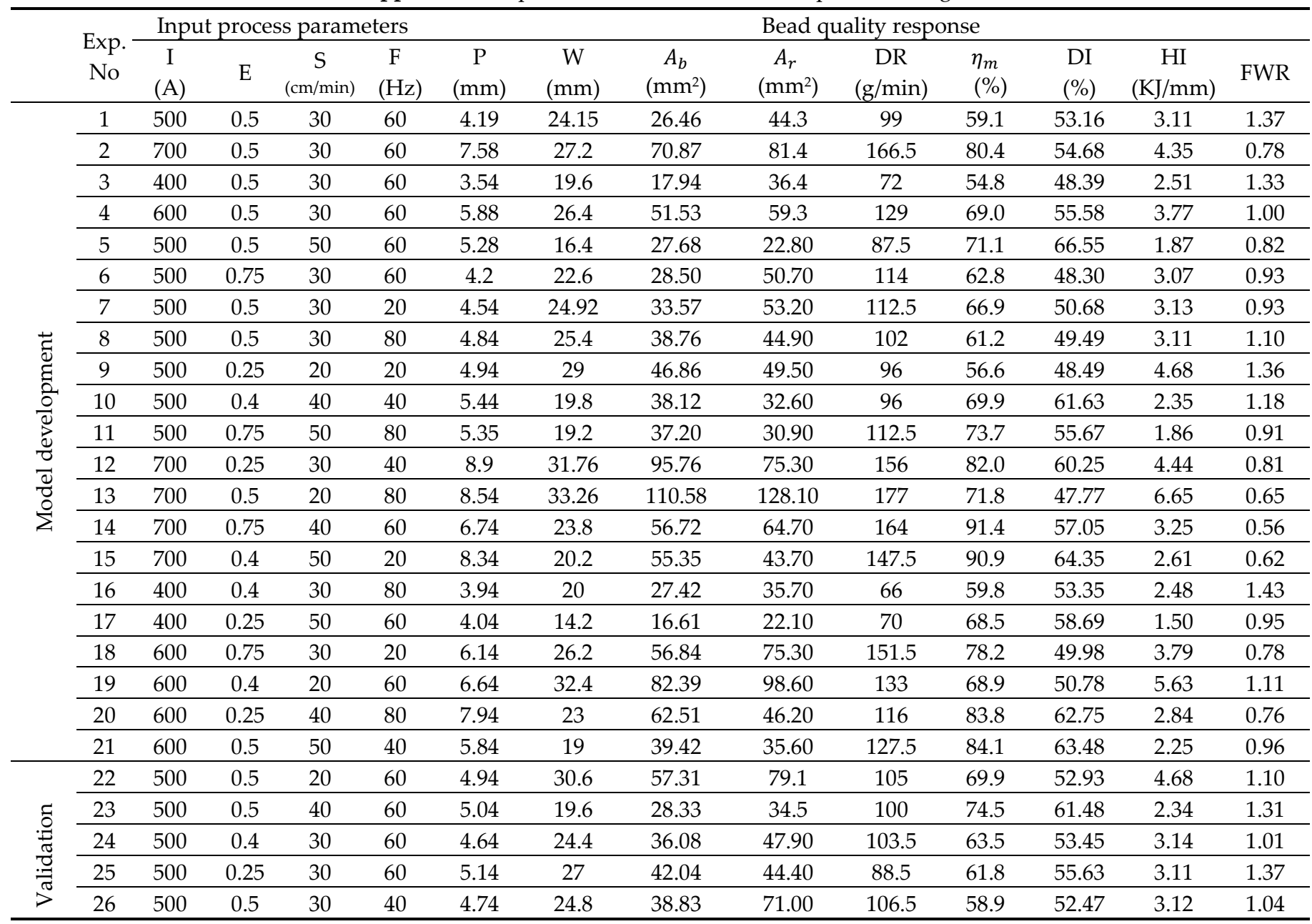

I-Current; E-EN ratio; S-Welding speed, F-frequency; P-Penetration; W-Bead width; $A_{b}-$ Bay area; $A_{r}-$ Reinforcement area; $\mathrm{D}-$ Deposition rate; $\eta_{m}-$ Melting efficiency; HI-Heat input; FWR-Flux-wire ratio. 